Original Research Paper

\title{
'Someone to Open Each and Every Door': Construction Grammar as a Learner Grammar: The Case of English Indefinite Pronouns
}

\author{
Randal Holme \\ School of Education, Oxford Brookes University, Oxford, UK
}

Article history

Received: 07-05-2015

Revised: 22-05-2015

Accepted: 01-06-2015

\begin{abstract}
This paper sets out an applied model of Cognitive Construction Grammar along three dimensions: Compositionality, form as a vehicle for promoting the emergence of grammatical meaning from lexical meaning and construal. The model of Cognitive Construction Grammar put forward here implies that the Applied Linguist may have to collect and explain a wider repertoire of grammatical forms than were considered previously. This extended repertoire may have the advantage of giving the learner a deeper understanding of semantic constraints on how we use a particular construction. It also means that forms once considered idiomatic are now being studied as productive and hence grammatical on some sense. The disadvantage is that we have to deal with a larger number of forms and have no clear principle as to where grammar learning ends and lexical or idiom learning begins. This paper discusses the question of what to include under the rubric of grammatical description and how to include it in relation to the SOME-and-ANY-SERIES (somebody/anyone, etc.) indefinite pronouns. It asks how this applied model of construction grammar affects what we present to learners by looking first at the formal attributes of the English SOME- and ANY-SERIES indefinite pronouns themselves and then at some of the types of clause in which the SOME-SERIES appears.
\end{abstract}

Keywords: Construction Grammar, Learner Grammars, English Indefinite Pronouns

\section{Introduction}

With his 'fundamental difference hypothesis', Bley-Vroman (1990) claimed that the inability of second language users to wean themselves off a quite limited array of chunked forms was due to their having passed the critical age of access to their Universal Grammar. Second language learners depended on prefabricated lexical phrases because they were unable to develop the natural syntax that first language speakers could naturally access. However, others have pointed out how the learner problem may in fact lie not in a failure to use a productive grammar but in a failure to establish the repertoire of 'lexical phrases' that native speakers seem to command (Nattinger and DeCarrico, 1992). Forms such as 'as it were, take lightly, wishful thinking' or 'it goes without saying' are treated as essential to the production of a native-like discourse. From this perspective, the problem for learners is not so much an overuse of fixed forms or chunks but a failure to acquire enough of these lexical phrases to achieve a native-like expressivity.

Holme (2013) has argued that a failure to understand the cause of many second language errors lies in a larger failure of linguistic description. A crude dichotomy between what is lexical and what is grammatical means that the true nature of the learner problem is misunderstood. Examples 1-2, taken from a corpus of Hong Kong students' academic writing illustrate the type of problem over which the intermediate or advanced learner often stumbles:

(1) The enthusiastic behaviour which teacher performs (author's data, 2010-2011)

Some might call Example 1 a collocational error, or one that relates to failure to find the right lexical phrase for 'performs'. In a Cognitive Construction Grammar (CCG), correlations should be rationalised by an 
understanding of the semantics of words and of the forms into which they do or do not fit. Generally the complementation of this verb 'perform' profiles 'a role' or 'play'. The error in Example 1, therefore, seems to be one we would categorise as lexical because it is finally about a failure to grasp the semantics of 'perform'. In construction grammar, however, grammaticality is finally always about finding the right fit between words. The decision as to whether Example 1 is a grammatical or lexical error is therefore more difficult to make.

To understand the problem of how to categorise Example 1, let us consider an imaginary type of error that is similar in some ways. Thus, we hear a learner say 'I go the car' instead of 'I start the car'. A traditional approach might categorise the error as grammatical because it begins in a failure to understand the intransitivity of 'go'. In CG, however, the difference between this error and that in Example 1 can be put down to productivity and both might be treated as lexical in one sense and grammatical in another.

Consider Example 1 first. If we treat 'perform' as a fixed term then the error is about the type of complementation that this verb's profile will allow. 'Perform's' range of possible complements is semantically limited (e.g., scene/role/part, etc) but in fact quite broad as the number of roles and parts is potentially large. The error therefore involves a productive and hence grammatical meaning or schema. To understand the schema we have to grasp what is 'performable' in Anglophone culture. This meaning is productive because more than one solution is possible, be it 'Iago', 'Othello', or 'role'.

There is a sense in which 'Go the car' could be treated similarly or very differently to Example 1 according to the perspective taken. Thus, if we treat it similarly, we could say that this is about the semantics of 'go' in the way that Example 1 is about the semantics of 'perform'. Arguably, 'go' has its complementation built into its meaning. Thus when we say 'I go home' we are assuming a complement, perhaps a reflexive (I go myself home). However, there are a large number of verbs that do not need to state their complement. Arguably, the large number of verbs that are traditionally called intransitive all have this built-in complementation (Langacker, 2008). We might therefore be discussing not just the semantics of a verb but that of a large group of verbs, or all intransitives. 'Go the car' therefore suggests a failure to grasp a very broad semantic principle, that of 'intransitivity' and it is these broad principles which are normally held to constitute a grammar.

For those interested in using CCG to produce an inventory of constructions that will help learners of English we can now see we have something of a problem. If we look at constructions at the level of which word fits with which we will look at a very much larger inventory of forms than was traditional. Thus we might need to look at constructions particular to every verb whose complementation is semantically constrained in any way that is less than obvious. For example, we might consider how and why 'suggest' does not fit with the ditransitive argument structure that is used by the learner in Example 2. If on the other hand we confine ourselves to meanings which like intransitivity seem to apply to larger sets of words we may leave the learner in the same place as previously, that is with insufficient guidance as to what word in fact constructs with what:

(2) (The teacher) suggests us choosing new vocabularies from the materials (author's data, 2010-2011)

This article will take the position that CCG (e.g., Broccias, 2013; Goldberg, 1995; Langacker, 1990) can furnish learners and teachers not just with an adjusted inventory of forms that may provide better guidance on how to address a given context but will also provide stronger insights into why such constructions take the form that they do. The insights that CCG provides could therefore help describe such errors as those made in Examples 1 and 2 so help learners avoid them. However, as we explore, these insights come with a potential price tag. The price is that learner grammars may have to inventory a much larger number of forms than previously. This will require a discussion about what we should put into a descriptive learner grammar and what we should leave out.

To respond to the problem of how CCG may challenge traditional notions of form, I first summarise and justify an applied approach to Cognitive Construction Grammar (CCG) by considering three core features and thinking briefly about how these may affect the way learners and teachers approach grammatical form. First, I stress constructions as combinations of other elements, or as compositional (e.g., Goldberg, 1995; 2006). Second, I consider the argument that meaning exists on a lexico-grammatical continuum where there is not always a clear dividing point between the lexical and grammatical (e.g., Croft, 2001). Third, I summarise how constructions are different ways of construing a topic or scene (e.g., Langacker, 1990; 2008).

The purpose of outlining this model will be to show how it can help identify an inventory of forms and their meanings that can help learners enrich their language in exactly the type of areas where our Examples 1 and 2 show them to be having difficulties.

To consider this objective in greater detail, I discuss English indefinite pronouns of the SOME- and ANYSERIES. I select these entities because they illustrate how CCG affords insight not just into which words construct with others but into how words themselves are constructed entities. Further, because these indefinite pronouns are nouns, they also illustrate how a construction grammar can move us away from a traditional view of the clause as built around a verb head 
and more towards its treatment as an argument structure built from an interaction of all its constituent meanings (Goldberg, 1995). I confine my discussion to the SOMEand ANY-SERIES, both for the sake of brevity and for how these forms exhibit some quite unusual properties of reference which can be made clearer by the approach to construction grammar that will be set out.

\section{CCG: A Three-Point Approach}

I address the notion of a construction's compositionality first. Basically, compositionality derives from the traditional constituency principle that smaller units compose larger ones. In CCG, we can see that the compositional principle which builds words will also build meaningful strings or constructions from those words. Like a visual composition, a linguistic one balances two contrary impulses. The first is for each element to retain its meaning. Thus if we begin by symbolising 'a house', perhaps with a drawing, this symbol must continue to mean what it does no matter where it is placed and what is done with it. The second is for that meaning to contribute to a larger composition. So if we place 'the house' on 'a hill', the house symbol gives up something of its meaning to the composition it helps create. We no longer see it as just 'a house' but as 'a house on a hill.' Some part of the symbols meaning is given to the composition it creates. To make this composition, two processes occur. The first is called inheritance (Lakoff and Johnson, 1999) and the second coercion (Michaelis, 2004).

Inheritance is broadly the use of existing networks of semantic features to interpret those that are new or unfamiliar. For example, in going south, an explorer from a northern latitude might encounter a palm tree for the first time. They recognise this novelty as a tree because of how it inherits certain features from the very different types of trees that they have encountered at home. In CCG we use inheritance to build or interpret new forms. Imagine, for example, that a speaker knows the form given in Example 3 below. They later encounter Example 4. They inherit the understanding from Example 3 that the construction in Example 4 expresses movement even when the verb 'laughed' does not.

Coercion is central to the idea of compositionality just advanced. It refers to how a construction adjusts the meanings of its constituents in a way that suits its larger meaning. In a straightforward argument structure construction such as 'I hate teachers', the clause coerces the meaning of 'teachers' away from that of simply 'people who teach' towards being also objects of hatred. The coercion is comprehensible because of how the construction inherits features from other transitive constructions, or from how a subject may be an agent causing a change of state to a patient. Constructions that are idiomatic, or which build meanings that seem to owe little to grammatical convention may in fact show the operation of 'inheritance' and 'coercion' more clearly. A much analysed example is the way construction (e.g., Jackendoff, 1990; Culicover and Jackendoff, 2005):

(3) I went the long way home

(4) I laughed all the way home

Formal analyses put the way construction outside the normal operations of grammar (Jackendoff, 1990; Culicover and Jackendoff, 2005) in part because of how it can give a transitive meaning to 'went' if a phrase with 'way' is the object (Example 3). By the same token, the construction can also coerce 'laughed' to a transitive meaning whilst making it part of a construction that represents motion without expressing this in the verb (Example 4). In CCG, the way construction simply offers a clearer and perhaps more extreme example of how grammar works. Most importantly, this is not some traditional argument about valency and the verb. The construction's meaning arises from how all its elements co-oerce one another to the meaning that results (Goldberg, 1995; 2006; Croft and Cruse, 2004; Croft, 2013). Thus if we remove 'all the way' from Example 4, the meaning breaks down (I laughed home).

As described, compositionality challenges traditional views of descriptive learner grammars in two fundamental ways. First, words are themselves constructions and there is no easy separation between morphemes that are considered grammatical such as the English plural-s and those that are considered lexical such as the English nominalising morpheme-ness. Arguably, a treatment of words such as the 'SOME/ANY-SERIES as compositions of morphemes now falls into the province of grammar. Second, forms such as the WAY-CONSTRUCTION should no longer be dismissed as exceptional or idiomatic but will instead be treated as items whose meanings and constraints require description and exemplification like the more abstract argument structures they instantiate.

The second principle of our model of CCG emerges from compositionality. This is our understanding that grammar and lexis are not entirely distinct entities and that grammar does not comprise an autonomous rule system that manipulates the forms and meanings of lexis (Croft, 2001). A construction is itself a symbolic entity. However, its meaning can be analysed at different levels of schematicity. To understand what schematic means in this case, take Examples 5-8:

(5) Surely there was something that she could do? (British National Corpus (BNC))

(6) Surely there is something that you can do?

(7) It/There+be+SOME-SERIES+MODIFIER

(8) It's someone we both know

(9) It was you who wanted to come (BNC) 
Example 5 expresses the not uncommon thought that when something is going badly for oneself or someone else, it ought to be possible to do something about it. A learner might store this as a chunk from which they might later generalise Example 6 where the tenses have been adjusted. We can now say that Examples 5 and 6 exemplify what we can call a must-be-something-wecan-do construction. In this construction, all the elements in italics in Example 6 are fixed. All the elements in roman could be treated as schematised, or have the potential to be realised or instantiated in different ways. For example, the COPULA verb 'be' has the potential to be instantiated as different tenses whilst maintaining a stative COPULA function (Examples 5 and 6).

Example 7 shows a CLEFT construction where the complement is always an indefinite pronoun of the SOME-SERIES. When specified at this level of schematicity, we can use our construction to produce Examples 5, 6 and 8. Basically, Example 7 describes a schema from which Examples 5, 6 and 8 inherit features. Example 9 takes us a step further. If we want to show a relationship between Example 9 and the other examples then we need an even more schematic description of the clause, which would be a description of a CLEFT.

We can now note that the more schematic the specification of the construction the more productive it becomes. Productivity, in this context, means the potential of the construction to be instantiated in different ways. For the language teacher, this creates something of a dilemma. Giving a construction a more productive specification gives learners greater lexical choice. Greater lexical choice increases the likelihood of learners selecting lexis whose meanings do not fit that of the construction. A failure to explore such meanings results in the type of error we saw with 'perform' in Example 1. In addition the learner may lack accurate and automatic ways to express the quite specific type of meaning represented by Examples 5 and 6 . Yet the opposite case is to overload the learner with a vast inventory of less productive forms.

The concept of a lexico-grammatical continuum has also engendered one of CCG's more contentious debates and this also has implications for our analysis of the process of acquisition itself. In $\mathrm{CCG}$, a schematic or grammatical meaning develops from the semantic parallels between substantive forms. Thus an infant acquiring English will build a transitive argument structure or an SVO schema from their encounter with various substantive examples of transitive clauses (Tomasello, 2003). The Radical Construction Grammar (RCG) proposal suggests that our notion of even such elemental parts of speech as nouns and verbs are products of how the construction uses words (e.g., Croft, 2001; 2013). At first sight, this proposal seems to be a logical extension of the view that we build grammatical schemas from semantic parallels between substantive forms. Like RCG, the model of construction grammar put forward so far also argues that the syntactic relations such as those specified in Example 7 (It + be + SOMESERIES + MODIFIER) are in fact semantic relations. For example, 'Modification' 'and 'Complementation' are categories that propose a general description of a semantic relation between words or phrases in relation to a Head. Yet it is difficult to grasp how this might work from the perspective of acquisition. Construction learning must start somewhere. It is difficult to understand how an infant would recognise certain types of meaning as coincident with one category of experience (say of things) and others as coincident with another (say of processes) if we had not developed some prior sense of such basic categories. In other words, to process a construction schematically, or perhaps as a transitive SVO, we need to recognise verb and nominal meanings as different. In their embodied notion of construction grammar, Bergen and Chang (2013) note how schematic word meanings for physical actions such as 'jump' form from what are called embodied simulations (2013). This proposes that a process is stored as images of how the body enacts it and that 'a thing' or nominal meaning builds from a sense of an entity as grasped, weighed or felt. It is these simulations that set down the fundamental distinction between verb and noun categorisations and not the construction alone.

In essence, a discussion about the extent to which grammatical categorisations emerge from constructions or from basic experience is a debate about the extent to which a language either divides experience into meanings or experience proffers a priori categorisations of experience for symbolisation as language. The resolution of this discussion requires an implausible separation of meaning that is linguistically shaped from that which is derived from experience. The more realistic argument is that linguistic and experiential meaning become mutually constitutive as language itself develops. Treating all grammatical categorisation as a product of the construction is itself a form a reductivism where it is language which always produces how we construe the relations between things and where we have no experience of such relations to find represented in the construction.

Yet the RCG argument does remind applied linguists how even meanings as schematic and fundamental as those of grammatical categories must be reworked or reconceptualised within the systems and cultures of whatever language is being targeted. At the same time, it has to be recognised that the new language is not manufacturing these types of meaning but is instead reworking some common and very basic attributes of experience. Learning new grammatical constructions is then both the 'transfer' of category meanings from a first language and the adaptation of them to how they are shaped by the second. Thus, Example 2 (teacher suggests us..) shows that the grammatical relations of the 'ditransitive' have been grasped at some level, or perhaps transferred from the user's native Cantonese. However, the error also shows that these relational 
meanings still require some adaptation to the constraints that English places upon them.

Our third key feature of CCG is its treatment of a construction as a construal of meaning. The grammar of a language symbolises the different ways in which an embodied mind can construe its reality. Basically, the schematic meanings of a language allow us different treatments of the same phenomena. As an example, take the behaviour of uncountable nouns in English. English teachers often introduce nouns to beginning learners as either countable or uncountable. Mass nouns such as 'water or stone' are called uncountable. But more advanced learners find that most mass nouns can be used as countable as in 'a fizzy water' or 'a fine powder'. What the advanced learner needs to understand is how countability is a form of construal and not a rule that insists we see something one way and not another. Thus when we talk about 'wine', we should not start from the assumption that we are using an uncountable noun but are using one that can be construed in different ways. We can thus treat 'wine' as unbounded mass (do you want some wine), as a generic uncountable (wine makes me tired), or as a bounded singular form (a nice wine). Grammar, then, offers a series of choices about how we construe a meaning.

\section{Indefinite Reference}

Keeping in mind the three facets of a construction defined above, I will now consider English indefinite pronouns of the SOME-/ANY-SERIES (someone, somebody, something, anyone, anybody, anything) with a view to exemplifying how building a construction grammar for learners might change the inventory of forms we make and the explanations of them we produce. As noted, an interesting aspect of CCG from an applied perspective is how it can sometimes account for the semantic motivation of form at both the level of syntax and morphology. I therefore begin with morphology or word construction and look at how in some cases the way that morphemes combine to create meanings can still be transparent.

Pronouns have excited some interest in Cognitive Linguistics, in part because of Fauconnier and Turner's (1997) theory of mental spaces and the insight it affords into the properties of reference (Taylor, 2002; Radden and Dirven, 2007). In Example 10 'the tree' instantiates an exemplar of the tree schema that has already been made familiar to the reader. Thus, we will hold a schema for a tree open in one mental space and put in another the particular instance to which the definite article refers (Radden and Dirven, 2007). The schema will probably consist of various salient features of the trees we have seen (Lakoff, 1987) and the instance will hold the particularities to which the text refers, here the fact that it is a 'fruit tree':
(10) The eldest brother was lying under the tree, keeping guard over it to make sure nobody stole the fruit $(\mathrm{BNC})$

The anaphoric reference of the pronoun 'it' in Example 10 also requires two mental spaces. This is because the pronoun itself is a word with its own natural gender and referential meaning that must be processed as part of a construction. Thus, as shown here, 'it' is a complement of 'over'. At the same time, the word must gather the larger part of its meaning from what it refers to 'the tree'. We therefore have to hold open two mental spaces. One in which to hold what 'it' refers to (the tree) and one in which to process 'it' as a meaning that takes up grammatical relations elsewhere in the construction.

A theory of mental spaces can help explain the semantic differences between the indefinite referents of the English SOME-/ANY-SERIES. Further, the different ways in which these two sets of indefinite pronouns exploit mental spaces is a function of the different ways in which they are constructed. I take the SOME-SERIES first.

A non-compositional construction is not necessarily interpreted through the elements of which it has been built in the way that CALL+ED must be interpreted as 'call' with a past morpheme in order to distinguish it from CALL. As Hilpert (2014) points out, we retain little sense of the formal and semantic separation of the components of a term such as 'REAL+LY'. The reason for this is doubtless the frequency with which the adverb is used and the fact that it has established a meaning which does not need to be assembled from its constituent morphemes. 'REAL+LY' therefore evidences not coercion but what we might call submersion, or process where the elements of constructions such as 'really' have yielded their meanings up to the larger composition they have created. Whilst the SOME-/ANY-SERIES also show submersion, the semantic result can be analysed by looking again at the constituents from which it is compiled.

'-ONE' can be a pronoun that refers to an undefined member of a specified group or 'set' (Radden and Dirven, 2007). In what we call the one-of-a-kind construction we see how the set defines the category that the referent is a member of. In Example 11, this set is specified as 'the author's most delightful servants'. 'One' can then be said to refer an unidentified instance of that category (Examples 11-13):

(11) Mrs Meacock is one of the author's most delightful servants (BNC)

(12) You are one of our new neighbours, from Sunset Cottage

(13) BAT Industries, yesterday sacked one of its big bankers

'Some' is generally an uncountable or plural indefinite determiner. Less commonly it can determine a 
singular noun as indefinite as in Example 14. Referring to someone as 'some person' can in fact be rude because the construction stresses how we find their identity insignificant. When 'SOME-' and '-ONE' construct together, the indefinite determiner 'SOME-' ensures that-ONE is no longer just indefinite in the sense of failing to specify which instance is being talked about, the-ONE is indefinite in respect of the category of things from which the instance comes, or its set. 'SOME-' attributes to '-ONE' a randomness in respect of its category. This meaning makes 'someone of the author's most delightful servants' ungrammatical because it expresses the semantic contradiction of an unknown referent that we know. To make the someone of... constructions grammatical, the OF-PHRASE must specify attributes or aspects of the referent as in Examples 15-17 and not its set identity as in Examples 11-13. Naturally there are points of overlap between our notion of an identifying set as in Example 13 and of an added attribute as in Example 15. Example 16 shows this kind of overlap and interestingly both 'one' and 'someone' could be used here, which may reflect how an attributive meaning is overlapping with one of category definition.

(14) Some person noticed them and hated them for what they were (BNC)

(15) Mrs Meacock is someone of high calibre

(16) I've no wish for someone of unknown parentage to inherit after my death

The composition of the morphemes 'SOME-' and 'ONE' gives the type of reference shown in the mental space diagram at Fig. 1. The first space holds a referent and the second the pronoun as it is used in the text. The referent's identity is undefined, however. I therefore mark the referent with a question mark. Unlike in the one-of-a-kind construction, the referent's set is irrelevant or unidentifiable. The text may, however, confer attributes on the referent as it unfolds. I discuss this as 'veiling' below.

The ANY-SERIES pronouns can also be seen as fairly transparent from the perspective of how different elements combine to create a meaning. In the one-of-akind construction, 'one' refers to a single but unspecified member of a defined set. ANY-distributes the reference across the set. The ANY-SERIES has a 'free-choice meaning' (Kadmon and Landman, 1993) and can be imagined as a deictic gesture where the finger of the pronoun's user points out each the group member and defines it in its entirety but never stops at any member. No referent is thus ever singled out from the set. The effect is to make the existence of that referent speculative. In Examples 17-18, I show the contrast between the 'some' and 'any' reference. In Example 17, which is fabricated by the author, the referent is extant but with an unknown identity or set. In Example 18, the set first comprises people governed by the ordinance (any-). '-One' refers to an individual that may be singled out from the set by an attribute (found..drug). Example 19 is a construction which some users might create as a substantive form for contexts where we despair of identifying the referent. It shows how we use the ANY-SERIES with a belief that the referent may never come into existence. The use of the ANYSERIES in negative constructions or interrogatives that expect negative answers follows from how it builds a reference to what may never exist, or from an individual that remains inside its set:

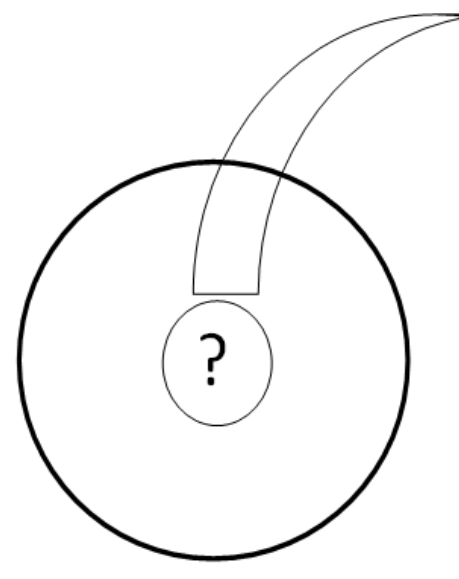

Extant but unknown Referent (instance of an unknown category)

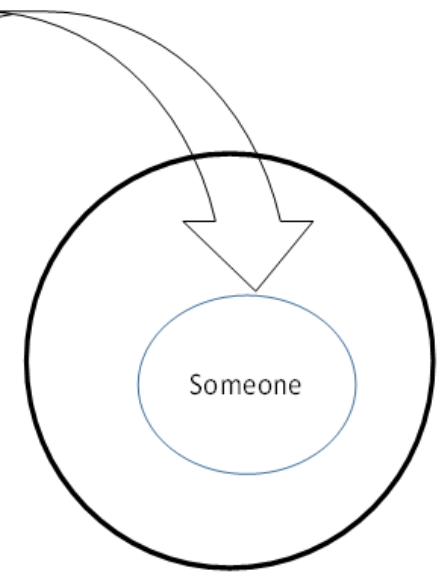

Someone

Reference

Fig. 1. The some-series and the use of mental spaces 


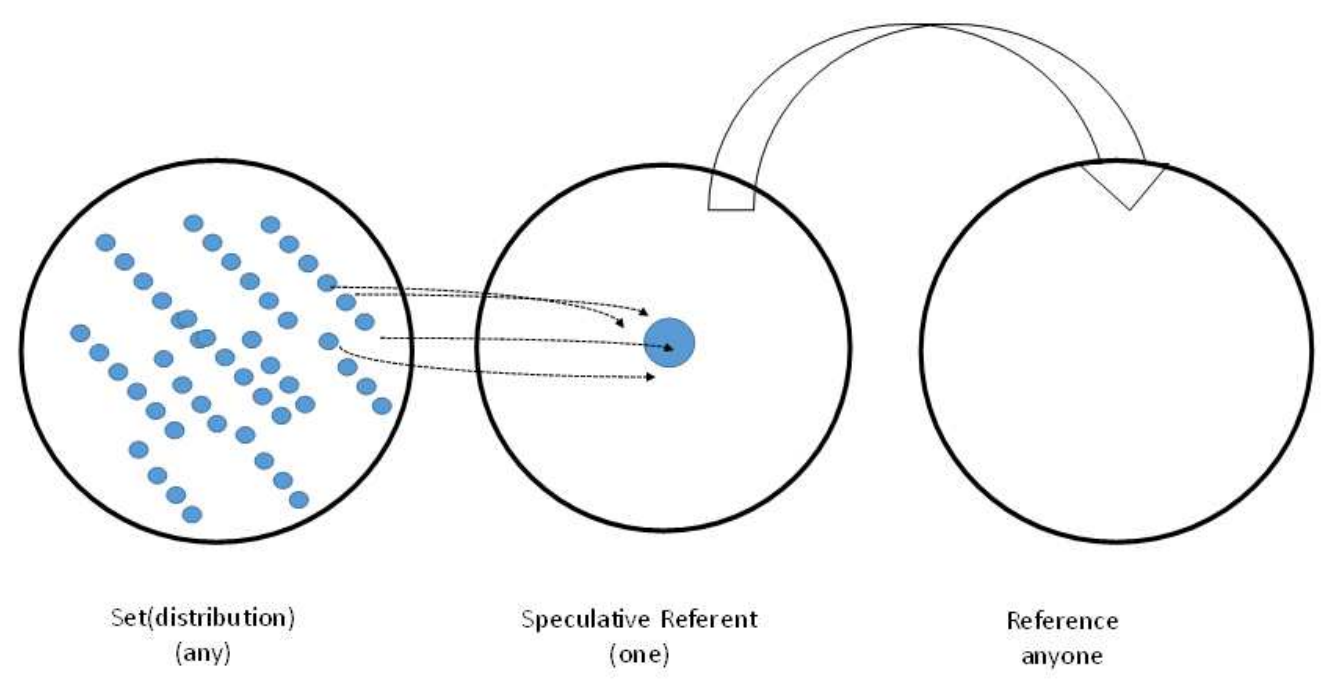

Fig. 2. The any-series and the use of mental spaces: Indefinite reference (pronoun), speculative referent (person found with an illegal drug), the set from which the referent comes (a population)

(17) Someone found with a small amount of an illegal drug was charged by the police.

(18) Anyone found with even a very small amount of an illegal drug can be charged by the police (BNC)

(19) It could be anyone (BNC)

Two mental spaces are therefore needed to build the reference for the ANY-SERIES, one to hold the set from which the referent may or may not be drawn (the meaning of ANY-) and the other to hold the hypothetical referent itself (the meaning of-ONE). I show this in Fig. 2.

\section{Constructions with Indefinite Pronouns or Indefinite Pronoun Constructions}

The above analysis shows how there may be connections between the way morphemes construct word meanings and the types of phrasal and clausal construction in which the word can appear. Thus we noted how the SOME-SERIES will not accept modifiers that give the category of the referent because this amounts to a contradiction. This carries us forward from looking at word forms themselves towards giving thought to how grammatical forms such as indefinite pronouns have key roles in establishing phrasal or clausal constructions. Learner grammars of English such as Cambridge Grammar of English (Carter and McCarthy, 2006) are now corpusbased in the sense of both exemplifying forms with authentic examples and basing their analysis of how to use a given item on what co-occurs with what. In their pattern grammar, Hunston and Francis (1996) took this form of analysis further by putting forward a grammar that consisted of word-based patterns. Thus reporting verbs, some adjectives and some nouns are analysed as having a 'that.. pattern'. Two examples for 'decision' are given in Examples 20-21:

(20) They can't trust a decision that they make there and then (BNC)

(21) He defended the Government's decision that its rules on cross-media ownership should not apply (BNC)

A risk with this pattern or collocation-based views of form is that they force learners back to a rote approach where they can only reproduce constructions as learnt chunks, Examples 20-21 show this through how their common pattern exemplifies different constructions with different constraints. In Example 20, the 'thatclause' is a post-modifier of 'decision'. In Example 21 , it is a complement. Each construction can therefore be generalised with different forms in different ways. Example 20 can be generalised as a relative clause with a different relative pronoun. As a post-modifier, the construction tells us something about the nature of the decision or something as to where and how it was made. Example 21 is a complement which must set out what was decided.

A CCG approach on the other hand suggests that we exploit the corpus based-analysis of pattern-grammar to identify constructions often overlooked by a more traditional view but that we then use that data to analyse whether the forms have a common schematic meaning. We can therefore assume that while word patterns do not by themselves identify constructions, they may show where such forms reside. Thus, after we have found that Example 22 shows a different construction to Example 21 , we might next start to explore its productivity and the constraints thereupon by considering the type of schematic meaning involved. Thus we might find that 
Example 22 is not a construction that unfolds complements that tell us the content of a 'decision' but which tell us the content of an array of what we might term 'cognitive' nouns or nouns which summate thought and speech processes (view, opinion, idea, understanding, etc). Two issues now emerge, not just for our discussion of indefinite pronoun constructions but for how we specify a learner descriptive grammar generally. First, we have made a reference to the term 'cognitive nouns'. We have also described how the 'thatcomplement' tells us the content of such nouns. Such terms reveal how helping learners towards a more productive and accurate use of constructions will require some development in our understanding of how to describe their meanings to them. Second, although we have moved away from tying patterns to word occurrences we are also dealing with narrower categories of meaning than are traditionally contained in such functional descriptors as SUBJECT or COMPLEMENT. These narrower categories are likely to produce an overwhelming inventory of forms and may do so without a suggestion as to what should be presented to learners and what should not.

A problem, here, is that CCG cannot by definition specify the set of forms which comprise what was called a native speaker competence. The way in which constructions are specified will vary from individual to individual as CCG rules out the possession of a standard competence through which all members of a language using community parse what they hear and say. If we look back to Example 19 (It could be anyone), we can treat this on multiple levels. First, we can present it as a substantive form, or useful phrase for moments when we don't know who a culprit is. Second, we can add an element of productivity by suggesting that other expressions of deontic modality with low commitment are possible (It might be anyone). Third, we can treat the indefinite pronoun as substitutable with suggestions as to who the culprit is (It could be the butler). Finally, we might say this is simply a COPULA clause (He is James). The problem for those interested in producing the construction grammar of a language is to know the level of productivity at which it would be most useful to explore such forms with learners.

In the case of English indefinite pronouns, we might want to differentiate two types of form: Constructions in which indefinite pronouns occur and indefinite pronoun constructions. In the first type, the construction is really an example that shows how indefinite pronouns are used. In the second, the presence of indefinite pronoun is central to the chosen form and meaning. In this second case, the construction must show how it uses indefinite pronouns in a way that expresses a particular meaning. Finally, we need to be able to identify some type of formal pattern. Thus, Examples 20-21 are transitive clauses that have the common attribute of using an indefinite pronoun to express a subject whose identity is unknown. Beyond this and the common use of SOMEONE as a subject the constructions have little in common. In their relation, or lack of relation, one to another, the clauses are therefore no more than constructions with indefinite pronouns. Examples 22-23 share a meaning to a greater extent than Examples 23-24. Examples 22-23 address a context where we have to justify doing something mundane or unpleasant. Examples 22-23 also require deontic modality to express this meaning. Arguably, a productive construction with a specific type of meaning is starting to become identifiable. I show this by marking the SOME-SERIES and the modal verb in italics, or as possible fixed elements. However, we can also note that despite their expression of a context with common features, the constructions have somewhat different complementation patterns. In other words, we are saying these elements are the same construction when they are clearly grammatically different at another level. Yet if the emphasis is on the type of meaning developed around the presence of the indefinite pronoun this last point may be something we can overlook. Examples 22-23 are therefore starting to look like indefinite pronoun constructions and might be worth learner attention as a productive way to address a certain meaning:

(22) Someone has to look after our belongings.

(23) Someone has got to take the blame.

(24) Someone has had their hands in the till.

Examples 25-26 share with Examples 22-23 the combination of SOMEONE with a modal verb. But the modality is now epistemic and this creates a type of construction that expresses a quite different context. Here the meaning is one of speculation on a set of events but not on the identity of their protagonist:

(25) Someone must have seen the boy that night.

(26) Someone could have been hiding here when we came into the church earlier today.

(27) Someone must be producing them.

(28) Someone must have made them.

Examples 22-23 and 26-28 both form sets that are quite context specific. Each set could be identified as a productive construction with a particular purpose. The indefinite pronouns are central to each as even substituting them with a non-specific subject such as 'a person' will lose something of the construction's meaning. Each also depends on the presence of other elements and most crucially on the use of deontic or epistemic modality. We can therefore start to see how for the learner a construction grammar might identify a plethora of contextually useful forms, many of which will be missed by a more traditional analysis. However, 
decisions as to what constitutes a form that is worth discussion or identification depends on a judgement as to its having grammatically distinct elements (e.g., SOME-SERIES+EPISTEMIC MODAL) that are used to address a specific context. Such forms, however, are better thought of as types of construction in which indefinite pronouns appear than as grammatically distinctive indefinite pronoun constructions.

A clearer case of an indefinite pronoun construction would come from being able to show that their presence can create an unusual syntactic feature. Indefinite pronouns are helpful here because they defy normal English word order by setting up a N+Adj construction (Examples 29-30). Formal analyses have seen SOME-/ANY-SERIES+ADJP constructions as types of reduced predications or relative clauses (e.g., Larson and Marušič, 2004). Thus, 'something wrong' (Example 29) is a reduced form of 'something that was wrong'. Yet, explanations that postulate the generation of one form from another do not fit with what Goldberg calls the what-you-see-is-what-you-get approach of Construction Grammar (2006). This construction should not therefore be seen as a transformation of something else but as a clear instance of a SOME-/ANY-SERIES + ADJ construction:

\section{(29) I needed to be someone else, someone new (30) Did they do something wrong?}

Yet there is still a difficulty of specification even here. SOME-SERIES+ADJ can be seen as simply a grammatically distinct version of a construction that conforms to more normal English word-orders. Thus Examples 31-37 all contain a SOME-SERIES+MOD construction but show a common pattern because the post-modifier is not an adjective. Furthermore and for reasons I will examine, it is perhaps this SOMESERIES+MOD construction which is the most useful and productive one from a learner perspective.

The interest of Examples 31-37 lies partly in how the SOME-SERIES+MOD is the complement of a COPULA argument structure. This argument exploits how the SOME-SERIES pronouns have a kind of pure schematicity. It uses the pronouns to establish a semantic space that is almost empty bar its representation of a nominal meaning. The pronouns are there not to carry meaning but to have meaning built around them through modification. Such constructions go to the root of the creativity that construction composition allows. They make it possible to assemble nominal meanings from other elements and, as it were, create nouns to order or to the specifications that a given context requires. They are therefore worth pointing out to learners as a means to build the meanings they need. Example 31 shows how such meanings can be highly specific:

(31) What he thought he needed was someone with the public fame to take over the leadership and to hold a candle to the great names of Lloyd George, Austen Chamberlain, Churchill, Birkenhead and Balfour (BNC)

(32) He employed somebody to clean up for him (BNC)

(33) You have become someone of consequence (BNC)

(34) He realized that he was somebody who could control people (BNC)

(35) An archaeologist is somebody who looks for clues (BNC)

(36) I'm not someone who is going to be the same person in every film (BNC)

(37) I'm just someone who's into what he's doing (BNC)

In Examples 31-37, the use of the SOMESERIES+MOD construction inside a copula grounds a subject onto the features that the user most wants to emphasise. So, in Example 32 the referent is not just to a 'cleaner' but to a person who cleans for a particular person. In Examples 32-33, the subject reduces themselves to an identity with one significant feature. Their larger identity is subsumed by their being 'of consequence' or being able to 'control people'. Example 35 is pseudo-definitional in sense of using the construction to define an entity not in the way a culture normally does but in the manner in which an individual language user sees fit. Example 36 is a refusal to assume such a mono-dimensional identity. Example 37 downplays any complexity of motivation.

I call these Veiling Constructions because of how they disguise a subject's larger identity in order to make some of its features salient. The known subject undergoes a process of 'de-definition' (you have become someone) to highlight a specific attribute (of consequence). Again, we note a productive but semantically specialised use of the COPULA argument structure that is in part defined by the presence of the SOME-SERIES pronoun. Such forms merit learner attention if only because they illustrate how the more schematic COPULA Argument structure can be used to build the meanings they want to express.

\section{Conclusion}

The paper sets out what it considers the most useful attributes for an applied CCG approach to language. It argues that CCG differs from other modes of grammatical analysis most markedly in its treatment of the attributes of composition, the lexico-grammatical continuum and construal. It then discusses how this type of analysis might change our view of what a language learner grammar should comprise by considering the case of English indefinite pronouns. It argues that CCG means we can relate word meaning and types of reference to word construction, showing the semantic motivations that lie behind forms. It further charts the new problems of providing learners with a set of useful 
constructions when these will be subject to various levels of semantic and formal overlap. One result maybe that there is less agreement about what the grammar of a language should comprise. Another risk is confronting the learner with such a large inventory of forms that they give up before they have begun. There is also the potential for organisational problems because of how a given construction can be treated at different levels of schematicity and hence productivity. Thus a Veiling Construction could simply be regarded as a type of copula argument structure and hence not really a productive form in its own right. Yet there is also a bonus in this type of construction overlap as recycling a more productive construction (the copula) through a more specialised use of it (veiling) may reinforce how to use two types of form.

In general, the future pay-off for learners could be considerable as it may mean providing learners with an inventory of forms whose more specialised but still productive nature ensures a more accurate understanding of how a language is used to tackle a given context. CCG may finally be incorporated as part of a teaching approach that affords to learners themselves the flexibility to build their own inventories of constructions and so to explore the productivity and the constraints of the forms that they collect.

\section{Acknowledgement}

The author acknowledges the considerable input of the referees of this article and of the editor of this edition of the journal

\section{Funding Information}

General Research Fund of the Research Grants Council of the University Grants Committee of Hong Kong.

\section{Ethics}

This article is original and contains unpublished material. The corresponding author confirms that all of the other authors have read and approved the manuscript and no ethical issues involved.

\section{References}

Bergen, B. and N. Chang, 2013. Embodied Construction Grammar. In: The Oxford Handbook of Construction Grammar, Hoffman, T. and G. Trousdale, (Eds.), Oxford University Press, Oxford, pp: 168-190.

Bley-Vroman, R., 1990. The logical problem of foreign language learning. Linguistic Analysis, 20: 3-49.

Broccias, C., 2013. Cognitive Grammar. In: The Oxford Handbook of Construction Grammar, Hoffman, T. and G. Trousdale, (Eds.), Oxford University Press, Oxford, pp: 191-210.
Carter, R. and M. McCarthy, 2006. Cambridge Grammar of English. Cambridge University Press, Cambridge.

Croft, W., 2001. Radical construction grammar: Syntactic theory in typological perspective. Oxford: Oxford University Press.

Croft, W., 2013. Radical Construction Grammar. In: The Oxford Handbook of Construction Grammar, Hoffman, T. and G. Trousdale (Eds.), Oxford University Press, Oxford, pp: 211-232.

Croft, W. and D.A. Cruse, 2004. Cognitive Linguistics. 1st Edn., Cambridge University Press, Cambridge.

Culicover, P.W. and R. Jackendoff, 2005. Simpler Syntax. 1st Edn., Oxford University Press, Oxford, ISBN-10: 0199271089, pp: 589.

Fauconnier, G. and M. Turner, 1997. Mappings in Thought and Language. 1st Edn., Cambridge University Press, Cambridge.

Goldberg, A.E., 1995. Constructions: A construction approach to argument structure. Chicago: University of Chicago Press.

Goldberg, A.E., 2006. Constructions at Work: The Nature of Generalisation in Language. 1st Edn., Oxford University Press, Oxford.

Hilpert, M., 2014. Construction Grammar and its Application to English. 1st Edn., Edinburgh University Press, Edinburgh.

Holme, R., 2013. Emergentism, Connectionism, Complexity and Cognitive Linguistic Models of Language. In: Handbook of Second Language Acquisition, Herschensohn, J. and M. YoungScholten, (Edn.), Cambridge University Press, Cambridge, pp: 605-626.

Hunston, S. and G. Francis, 1996. A corpus driven approach to the lexical grammar of English. Amsterdam: John Benjamin.

Jackendoff, R., 1990. Semantic Structures. 1st Edn., MIT Press, Cambridge Mass.

Kadmon, N. and F. Landman, 1993. Any. Linguistics Philosophy, 16: 353-422. DOI: $10.1007 / \mathrm{BF} 00985272$

Lakoff, G., 1987. Women, Fire and Dangerous Things: What Human Categories Reveal About the Mind. 1st Edn., The University of Chicago Press, Chicago.

Lakoff, G. and M. Johnson, 1999. Philosophy in the Flesh. 1st Edn., Basic Books, New York.

Langacker, R., 1990. Concept, Image and Symbol: The Cognitive Basis of Grammar. 1st Edn., Mouton de Guyter, Berlin and New York.

Langacker, R., 2008. Cognitive Grammar: A Basic Introduction. 1st Edn., Oxford University Press, Oxford and New York.

Larson, R.K. and F. Marušič, 2004. On indefinite pronoun structures with APS: Reply to Kichimoto, Linguistic Enquiry, 35: 268-287.

Michaelis, L., 2004. Type shifting in construction grammar, an integrated approach to aspectual coercion. Cognitive Linguistics, 15: 1: 1-76. 
Nattinger, J.R. and J.S. DeCarrico, 1992. Lexical Phrases and Language Teaching. 1st Edn., Oxford University Press, Oxford.

Radden, G. and R. Dirven, 2007. Cognitive English grammar. Amsterdam and Philadelphia: John Benjamins Publishing Company.
Taylor, J.R., 2002. Cognitive grammar. Oxford University Press, Oxford.

Tomasello, M., 2003. Constructing a Language: A Usage Based Theory of Language Acquisition. Harvard University Press, Cambridge, Mass and London. 